\title{
Effects of Exposure to Cigarette Smoke on Distortion-Product Otoacoustic Emissions in Rats
}

\author{
Raheleh Hashemi Habybabady, ${ }^{1}$ Seyed Bagher Mortazavi, ${ }^{1,}$ Ali Khavanin, ${ }^{1}$ and Ramazan Mirzaei ${ }^{2}$ \\ ${ }^{1}$ Department of Occupational Health Engineering, Faculty of Medical Sciences, Tarbiat Modares University, Tehran, IR Iran \\ ${ }^{2}$ Department of Environmental and Occupational Health Engineering, School of Health, Social Determinants of Health Research Center, Mashhad University of Medical \\ Sciences, Mashhad, Iran \\ "Corresponding author: Seyed Bagher Mortazavi, Department of Occupational Engineering, Faculty of Medical Sciences, Jalal Ale Ahmad Highway, Tarbiat Modares University, \\ Tehran, IR Iran. Tel: +98-9123562471, E-mail: mortazav@modares.ac.ir
}

Received 2016 August 09; Revised 2016 October 26; Accepted 2016 November 10.

\begin{abstract}
Background: Different types of direct and passive smoking have been reported to be associated with conductive and sensorineural hearing loss. In this study, we aimed to investigate the relationship between cigarette smoke exposure and cochlear dysfunction.

Methods: In this experimental study, 12 male Wistar rats were divided into 2 groups: control group without exposure and smokeexposed group housed in a whole-body exposure chamber (exposed to the smoke of 20 cigarettes; $9 \pm 1 \mathrm{mg}$ of tar and $0.8 \pm 0.1 \mathrm{mg}$ of nicotine per cigarette) for 8 hours a day during 10 consecutive days. The main and side stream smoke was generated in accordance with the federal trade commission (FTC) regimen (2-second puff with $35 \mathrm{~mL}$ volume and frequency of 1 puff per minute). Distortionproduct otoacoustic emissions (DPOAEs) were evaluated at a frequency range of 4620 - $9960 \mathrm{~Hz}$ at baseline and 1, 7, and 21 days after exposure. Repeated measures ANOVA and t test were performed for data analysis, using SPSS version 18.

Results: In the smoke-exposed animals, temporary hearing changes were significantly different from the baseline at a greater attenuation and higher frequencies $(\mathrm{P}<0.001)$. The amplitudes clearly recovered in the smoke-exposed group at 7 days after the intervention, and further improvement was observed until the end of the experiment. In contrast, DPOAE amplitudes remained consistent across time in the control group $(\mathrm{P}>0.05)$.

Conclusions: Subacute smoke exposure for 10 days resulted in the temporary reduction of DPOAEs. Chronic and subchronic effects of smoke on permanent hearing damage need to be investigated through further animal studies.
\end{abstract}

Keywords: Cigarette Smoking, Otoacoustic Emissions, Hearing Impairment, Rat

\section{Background}

Some ototoxic chemicals may lead to the damage or loss of sensory cells and peripheral nerve endings of the cochlea in the inner ear (1). In industry workers, apart from occupational exposure, the hearing level can be affected by chemicals in the cigarette smoke, as smoking is a common habit among these workers.

Cigarette smoking can promote oxidative stress by generating reactive oxygen species (ROS) and reactive nitrogen species, causing damage to the cell structure and impairing cellular function. Oxidants may be formed either directly by cigarette smoke constituents or in response to cell inflammation due to smoke-related oxidative stress (2). Furthermore, increased blood viscosity and oxygen reduction due to cigarette smoking can disrupt and damage the hair cells in the cochlea (3).

The association between smoking and hearing loss has been discussed with widely diverse outcomes. Some studies have revealed that all types of direct and passive smoking are associated with conductive and sensorineural hearing loss (4-9). Some studies have also reported this associa- tion under certain conditions. Moreover, the relationship between heavy smoking and poor hearing thresholds has been reported in populations without any major noise exposure $(10,11)$.

In a cohort study, the number of cigarettes per day and duration of smoking were related to hearing loss, mainly at high frequencies. The harmful effect of smoking on hearing was cumulative and permanent, as highfrequency hearing loss was detected in long-term smoke exposure (11). In addition, in an animal study, nicotine receptors were detected in the hair cells, indicating that smoking might produce direct ototoxic effects on hair cell function and reduce the potential of the hearing neurotransmission organ. Hair cell damage could be a result of inadequate available oxygen for the organ of Corti and insufficient available energy for the cochlea (12). On the other hand, some studies could not detect any association $(13,14)$.

The controversial results regarding the relationship between smoking and hearing loss are mainly related to confounders in human studies. There are many confounders at workplace, such as exposure to ototoxic agents 
other than smoke, noise, and antibiotic consumption, which might be responsible for this discrepancy. Additionally, self-report information about smoking dosage and lack of knowledge about various types of smoke exposure can explain this controversy. Therefore, it is necessary to control such confounding factors through in vivo studies.

Smoking is an established risk factor for the development of arteriosclerosis and consequently ischemia (15). The most reliable monitoring tool to follow-up cochlear ischemia and reperfusion is the otoacoustic emission (OAE) test, which shows a better performance than the gross cochlear potential (15). OAE is able to differentiate neurological and auditory sensory disorders and monitor changes in the cochlear status. OAE test provides information about the middle-ear function and active biological processes within the cochlea to determine the outer hair cell (OHC) cochlear mechanism (8).

Although some animal studies have mainly focused on the effects of each ototoxic agent on hearing, there is limited evidence in animal research about the combined effects of agents in cigarette smoke, including organic solvents (styrene, benzene, and toluene), asphyxiants (carbon monoxide and hydrogen cyanide), and heavy metals (1, 1624).

If a combination of cigarette compounds has synergistic or additive effects on hearing, as indicated in some ototoxic chemicals, development of hearing loss may be even accelerated (7). Therefore, in this study, we investigated the effect of smoking on temporary and permanent hearing loss in rats, using distortion-product OAEs (DPOAEs) as a type of OAE test.

\section{Objectives}

The aim of the current study was to investigate the relationship between cigarette smoking and DPOAEs in rats.

\section{Methods}

\subsection{Experimental Groups}

In this experimental study, 12 male Wistar rats (weight, $275 \pm 25 \mathrm{~g}$ ) were selected from the animal research center of Zahedan University of Medical Sciences, Zahedan, Iran and were randomly allocated into 2 groups of 6 rats, including the control group without exposure and the smoke-exposed group. In all rats, the external ear canal was examined for debris, and otoscopic examination was carried out to select rats with a normal outer ear canal and tympanic membranes.

\subsection{Animal Laboratory Conditions}

The rats were housed in polypropylene cages $(40 \times 20$ $\times 15 \mathrm{~cm}^{3}$ ) 1 week before the onset of the experiment. Tap water and food were available ad libitum, except during exposure. Temperature in the animal quarter was maintained at $21-23^{\circ} \mathrm{C}$ with a relative humidity of $40 \%-50 \%$. The lights were kept on for 12 hours (07.00 am - 19.00 $\mathrm{pm})$. We tried to reduce animal suffering as much as possible and decrease the number of animals needed for the experiment. All the procedures for care and use of animals were in accordance with the Declaration of Helsinki and approved by the ethics committee for experimental Medicine, Tarbiat Modares University, Tehran, Iran.

\subsection{Whole-body Exposure Chamber}

In this study, an inhalation whole-body exposure chamber was constructed. The primary design was based on the proposed considerations in previous studies, including reasonability, practicality, feasibility of animal activity, ease of maintenance, control of temperature and humidity, and maintenance of a continuous flow of fresh air (25-30). The chamber was fabricated from aluminum sheets with an outside dimension of $60 \times 45 \times 30 \mathrm{~cm}^{3}$ and an internal total volume of $177 \mathrm{~L}$.

Two funnels (height, $30 \mathrm{~cm}$ ) were connected to the top and bottom of the chamber with $52^{\circ}$ and $30^{\circ}$ slopes, respectively; this arrangement helped smoke disperse uniformly. In order to monitor the processes inside the chamber, all sides of the chamber were made of thick plate glass (Figure $1 A)$. The chamber had enough capacity for 6 cages (dimension, $15 \times 13 \times 17 \mathrm{~cm}^{3}$ ). Open wire mesh cages were made of stainless steel with a removable lid. Each rat was placed in a cage separately, and all 6 rats were placed systematically on parallel wire shelves inside the chamber during the experiment.

The chamber was tangentially connected to a custommade smoking machine through a short tube (diameter, $1 \mathrm{~cm})$ at the top of the chamber. Two centrifugal fans (Silent Servo Blower, SCBD24Z7 model, $10 \mathrm{w}$, Japan) were used to pump either smoke or fresh air into the chamber. The air and cigarette smoke flowed into the chamber in a mild swirling motion (due to the tangential connection of tubes) and passed through a perforated plate, installed on top of the chamber inside. As a result, the air and smoke were mixed and distributed uniformly throughout the chamber.

Near the bottom of the chamber, the exhaust air was drawn axially by an exhaust system through an individual exhaust duct. Inside the chamber, a thermometer humidity device (CEM DT-625, China) was used to measure temperature and humidity, maintained at $24-26^{\circ} \mathrm{C}$ and 


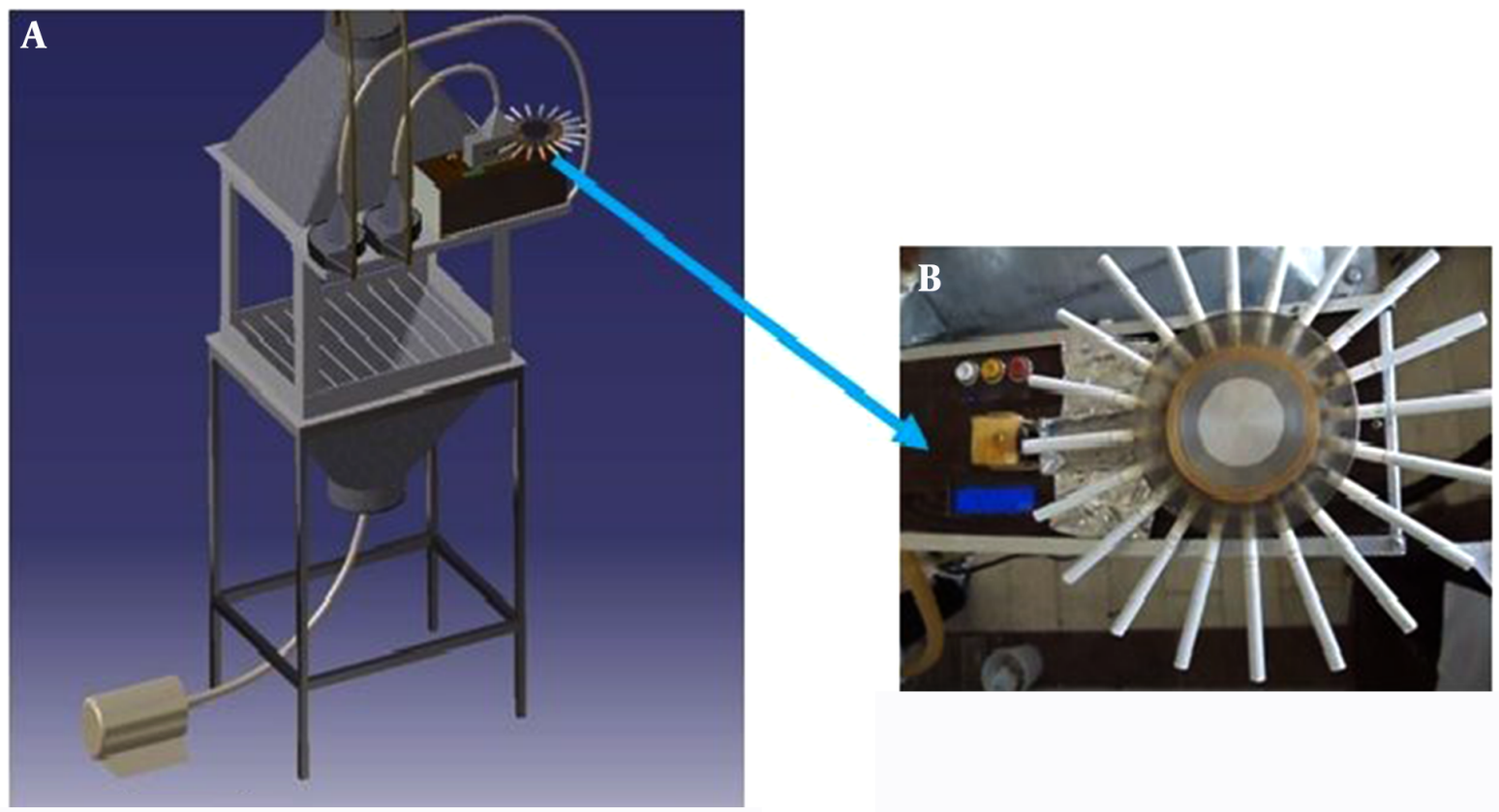

Figure 1. Whole-Body Exposure Chamber (A) and Smoking Machine (B)

$40 \%-50 \%$, respectively. The airflow w as m easured b y a thermoanemometer (VT100, Kimo Instruments, UK) and controlled by adjusting the total exhaust flow ( $5 \mathrm{~L} / \mathrm{min}$ ) through the chamber to maintain a negative static pressure (Figure $1 \mathrm{~A})$.

\subsection{Cigarette Smoke Exposure}

The rats were separately placed in cages inside the chamber and were exposed to cigarette smoke for 8 hours a day during 10 consecutive days (subacute exposure). The main and side stream smoke was generated in accordance with the federal trade commission (FTC) regimen (2second puff per minute with a volume of $35 \mathrm{~mL}$ and a flow of $1.05 \mathrm{~L} / \mathrm{min}$ ) (31). A custom-made smoking machine (Figure $1 \mathrm{~B}$ ), burning 20 cigarettes ( $9 \pm 1 \mathrm{mg}$ of tar and $0.8 \pm$ $0.1 \mathrm{mg}$ of nicotine per cigarette) was used during 8 hours a day.

The 8-hour exposure consisted of 2 repetitions of cigarette smoking cycles. In the first cycle, the rats were passively exposed to the smoke of 1 cigarette for 8 minutes (2 seconds of main stream and 58 seconds of side stream smoke), including 8 puffs per cigarette. In the second cycle, fresh air was allowed to be introduced instead of smoke for 17 minutes; these 2 cycles were repeated to burn 20 cigarettes.

\subsection{Air Sampling from the Chamber Atmosphere}

The test atmosphere was sampled, using a standard 0.9-cm nominal pipe, which was inserted in the chamber through 4 holes (diameter, $1.2 \mathrm{~cm}$ ), drilled, and then tapped on every side. Real-time sampling of the total suspended particulates (TSPs) was performed through a 4-cm hole in front of the chamber door. All the samples were obtained in the breathing zone of animals. Concentrations of 42.7 $\pm 5.7 \mathrm{mg} / \mathrm{m}^{3}$ for TSP and $300 \mathrm{ppm}$ for carbon monoxide (CO) were monitored and maintained in the chamber with a Microdust Pro Instrument (Microdust Pro ${ }^{\mathrm{TM}}$, Real-Time Aerosol Monitor Kit, Casella Cel Inc.) and a combustion analyzer (MRU Delta 65-s, Germany), respectively.

\subsection{Electrophysiological Test}

The rats were anesthetized with a mixture of ketamine $(68 \mathrm{mg} / \mathrm{kg})$ and xylazine $(8 \mathrm{mg} / \mathrm{kg}$ ) via intraperitoneal injection. The DPOAEs were measured inside a small soundattenuated chamber, lined with acoustic foam tiles with sound pressure not exceeding $42 \mathrm{~dB}$. All DPOAE tests were performed by a researcher, and the DPOAE measurements were repeated 3 times for each rat; the average value was considered as the DPOAE level.

A standard commercial cochlear emission analyzer (ECL 14091 apparatus, Labat's EchoLab Ltd, Italy) was used for the DPOAE test. The device was calibrated at the official 
branch of the company in Iran before starting the experiments. Calibration was also achieved automatically prior to each test for every ear. A frequency range of 4620 - 9960 $\mathrm{kHz}$ was considered for the bandwidth of DPOAE responses $\left(2 f_{1}-f_{2}\right.$, referenced to $\left.f_{2}\right)$ in order to avoid the influence of standing waves in the external meatus; also, 12 points were sampled per octave (32).

The primary $f_{2} / f_{1}$ frequency ratio was assumed to be 1:21. A nonsymmetrical DPOAE protocol was used to evoke responses, based on unequal primary tone stimulus intensities, i.e., L1 s L2; in fact, cochlear dysfunction can be more precisely evaluated with such stimulus intensities. The protocol was defined as follows: high level, $\mathrm{L} 1=60$ $\mathrm{dB}$ SPL and L2 $=50 \mathrm{~dB}$ SPL. All measurements $\geq 3 \mathrm{~dB}$ regarding signal-to-noise ratio (SNR) were used for the analysis. A heating blanket was used to keep the body temperature constant between 37.5 and $38.58^{\circ} \mathrm{C}$. DPOAE test was performed at baseline before the intervention and 1, 7, and 21 days after smoke exposure on the left ear of all rats.

\subsection{Statistical Analysis}

Shapiro-Wilk test was used to evaluate the normal distribution of the data. Repeated measures ANOVA and 2sample independent $t$ test were performed for data analysis, using SPSS version 18 . The significance level was set at 0.05 .

\section{Results}

At all frequencies, the baseline amplitudes were not significantly different between the smoke-exposed and control groups (Figure 2). In the control group, the DPOAE amplitudes did not significantly vary after 1,7 , and 21 days, while there was a significant difference between the baseline and 1-day post-exposure measurements $(\mathrm{P}<0.05)$, with a greater attenuation at higher frequencies (7500 $9960 \mathrm{~Hz}$ ) (Figure 3). The amplitude obviously recovered in the exposed animals from day 1 to day 7 post-exposure, and further improvement was observed until the end of the experiment (Figures 4 and 5).

One day after the intervention, the average DPOAE amplitudes in the smoke-exposed animals were attenuated by nearly $1.5-3.4 \mathrm{~dB}$ at lower frequencies $(4620-6720 \mathrm{~Hz})$ and $3.75-7.50 \mathrm{~dB}$ at higher frequencies $(7500-9960 \mathrm{~Hz})$, relative to the baseline (temporary hearing changes). Except for $4620 \mathrm{~Hz}$ frequency, the reduction was significantly different from the control animals. However, the average DPOAE amplitude gradually recovered after 21 days of exposure and approached the baseline. Therefore, DPOAE amplitude reduction, relative to the baseline, was not significantly different between the smoke-exposed and control

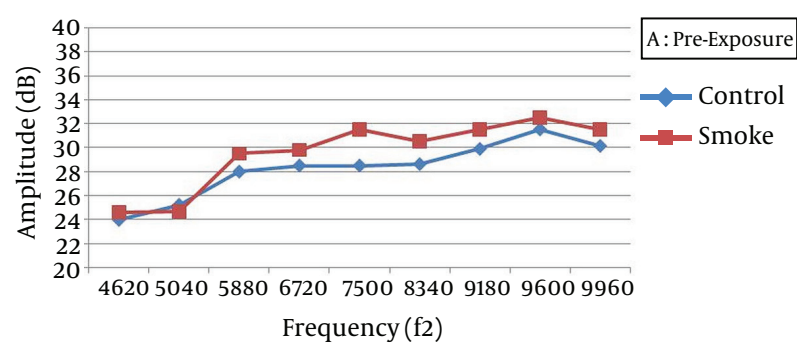

Figure 2. The Mean Baseline DPOAE Amplitudes (Signal-to-Noise Ratio) as a Function of $\mathrm{f}_{2}$ Frequency in the Smoke-Exposed and Control Groups

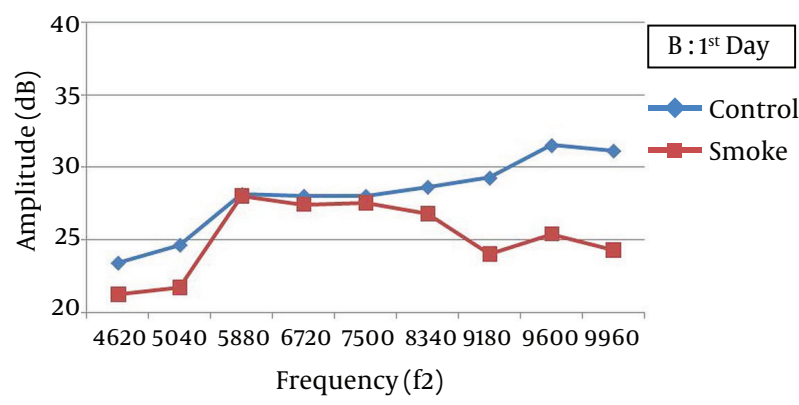

Figure 3. The Mean DPOAE Amplitudes (Signal-to-Noise Ratio) at 1 Day After Smoke Exposure as a Function of $\mathrm{f}_{2}$ Frequency in the Smoke-Exposed and Control Groups

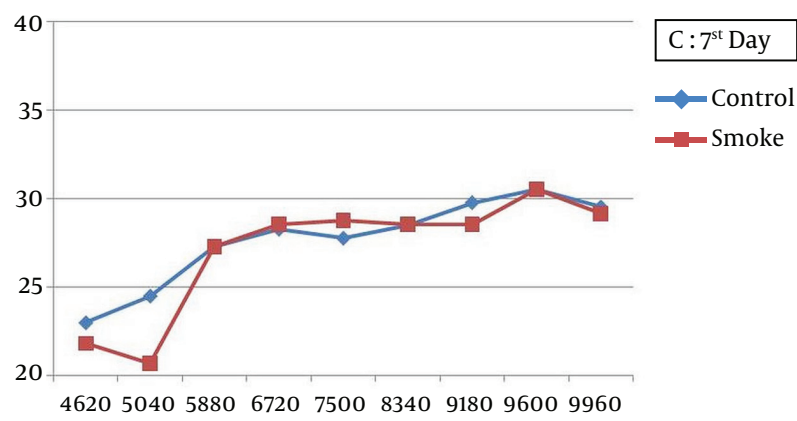

Figure 4. The Mean DPOAE Amplitudes (Signal-to-Noise Ratio) at 7 Days After Smoke Exposure as a Function of $\mathrm{f}_{2}$ Frequency in the Smoke-Exposed and Control Groups

groups after 7 and 21 days (Table 1). Also, 21 days after exposure, permanent amplitudes were not significantly different between the control and smoke-exposed groups at different frequencies $(\mathrm{P}>0.05)$.

The increasing trend of hearing recovery from day 1 to day 7 post-exposure was not constant at all frequencies. Based on the findings, at lower frequencies (4620 - 8340 $\mathrm{Hz}$ ), the amplitudes in the smoke-exposed group were not significantly different from the controls, while it was considerably larger at higher frequencies $(9180-9960 \mathrm{~Hz})(\mathrm{P}<$ 
Table 1. The Mean (Standard Deviation) DPOAE Amplitude Differences Between the Baseline And Postexposure Measurements in the Control and Smoke-Exposed Groups

\begin{tabular}{|c|c|c|c|c|c|c|c|c|c|}
\hline \multirow{2}{*}{$\begin{array}{l}\text { Variables } \\
\text { Frequency }\end{array}$} & \multicolumn{3}{|c|}{ Baseline-Day 1(Temporary Hearing Changes) } & \multicolumn{3}{|c|}{ Baseline-Day 7} & \multicolumn{3}{|c|}{ Baseline-Day 21 (Permanent Hearing Changes) } \\
\hline & Control & Smoke exposure & P value & Control & Smoke exposure & P value & Control & Smoke exposure & Pvalue \\
\hline 4620 & $0.62(2.21)$ & $3.40(1.34)$ & 0.082 & $1.00(0.50)$ & $2.80(3.27)$ & 0.314 & $1.00(1.15)$ & $2.50(1.50)$ & 0.145 \\
\hline 5040 & $0.62(0.75)$ & $3.00(1.00)$ & 0.015 & $0.75(1.50)$ & $3.33(2.89)$ & 0.179 & $0.75(0.50)$ & $2.17(1.04)$ & 0.059 \\
\hline 5880 & $-0.12(1.03)$ & $1.50(0.58)$ & 0.043 & $0.75(0.87)$ & $2.25(0.87)$ & 0.051 & $1.12(2.32)$ & $1.50(2.08)$ & 0.818 \\
\hline 6720 & $0.50(1.00)$ & $2.40(0.55)$ & 0.008 & $0.25(0.5)$ & $1.30(2.33)$ & 0.378 & $0.25(1.50)$ & $1.40(0.89)$ & 0.194 \\
\hline 7500 & $0.50(1.00)$ & $4.00(0.82)$ & 0.002 & $0.75(1.66)$ & $2.75(1.71)$ & 0.144 & $1.25(1.50)$ & $2.38(1.80)$ & 0.374 \\
\hline 8340 & $0.00(2.04)$ & $3.75(2.22)$ & 0.047 & $0.12(2.46)$ & $2.00(3.46)$ & 0.412 & $0.62(1.11)$ & $1.75(1.55)$ & 0.283 \\
\hline 9180 & $0.62(3.04)$ & $7.50(2.52)$ & 0.013 & $0.12(1.65)$ & $3.00(4.69)$ & 0.292 & $-0.50(2.27)$ & $1.25(3.40)$ & 0.425 \\
\hline 9600 & $0.00(1.15)$ & $7.12(2.53)$ & $<0.001$ & $1.00(0.82)$ & $2.00(0.82)$ & 0.595 & $0.50(1.29)$ & $1.38(0.75)$ & 0.402 \\
\hline 9960 & $-1.00(2.12)$ & $7.25(2.06)$ & 0.001 & $0.62(2.21)$ & $2.38(3.14)$ & 0.398 & $0.25(2.18)$ & $0.75(4.79)$ & 0.855 \\
\hline
\end{tabular}

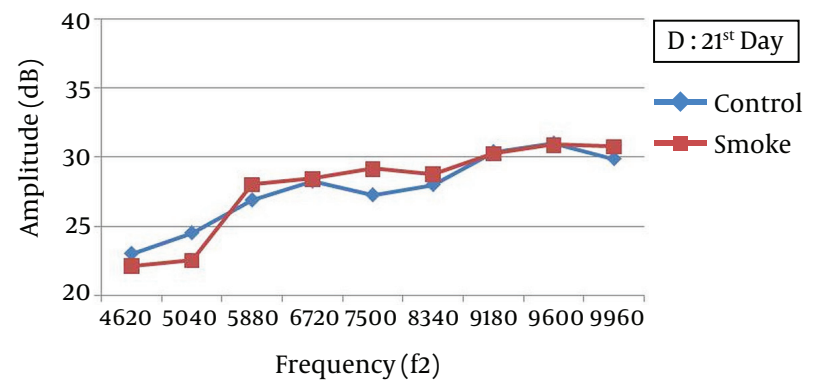

Figure 5. The Mean DPOAE Amplitudes (Signal-to-Noise Ratio) at 21 Days After Smoke Exposure as a Function of $\mathrm{f}_{2}$ Frequency in the Smoke-Exposed and Control Groups

0.05). Also, the DPOAE levels after recovery were not significantly different between the smoke-exposed and control animals at 7 and 21 days after the intervention (Table 2 ).

\section{Discussion}

After 10 days of exposure to smoke, a significant attenuation in the emission amplitude was observed at 1 day after exposure. The amplitude reduction was more pronounced at higher frequencies; this reduction was mostly recovered after 7 and 21 days. In a previous study, reduction in DPOAE levels, without concomitant changes in the noise floors, was different a mong smokers and nonsmokers (33), which is in agreement with the results of the current study. Also, further dose-dependent cigarette smoke deterioration was detected at higher frequencies. Therefore, smoking increases the vulnerability of the most basal portion of the cochlea, where higher sound frequencies are transduced $(5,11,12)$. It has been also shown that CO can mostly affect hearing loss at high frequencies, while long exposure to CO may affect low frequencies, as well (34).

The effect of smoke on the cochlea could be explained by possible pathophysiological mechanisms, i.e., chronic ischemia due to arteriosclerosis, elevated plasma viscosity, effect of chronic CO exposure, and direct activity of nicotine. The greater effect of CO compared to nicotine on temporary threshold shifts has been reported in the literature (35). Overall, smokers are at a higher risk of arteriosclerosis, as the number of pack years of smoking increases; also, elevated plasma levels have been reported in smokers (36).

Conversion of oxyhemoglobin to carboxyhemoglobin due to CO exposure can lead to hypoxia (37). Depletion of cellular energy stores, following prolonged hypoxia or hypoxia-ischemia, leads to neuronal and glial depolarization and release of excitatory amino acids into the extracellular space. Energy-dependent reuptake mechanisms become compromised, allowing glutamate to accumulate to excitotoxic levels. Also, overactivation of N-methyl-Daspartate (NMDA) receptors increases the intracellular calcium levels and initiates cellular processes, culminating in cell death $(38,39)$.

Additionally, as DPOAEs emanate from OHCs, which are enormously sensitive to changes in oxygen and blood supply, they can be influenced by anoxic insults. Several clinical studies have reported the association between reduced emission amplitudes and anoxic insults (33). The direct action of nicotine is also possible, since nicotine receptors are found on the OHCs of the cochlea (40). The cochlear artery, which ends in high-frequency regions, is prone to the effects of atherosclerotic changes; this finding has been also reported in smokers (33). Overall, cigarette smoking increases oxidative stress, which generates ROS either directly or through activation of inflammatory cells $(2,41)$.

In this study, DPOAE amplitudes started recovering after 1 day of exposure to smoke. They increased until day 7 and approached the preexposure level after 21 days of the intervention. In consistence with the present study, evidence suggests that acute $\mathrm{CO}$ exposure generally produces changes in the audiogram, which can be recovered during 
Table 2. The Mean (Standard Deviation) DPOAE Amplitude Differences in Postexposure Measurements in the Control and Smoke-Exposed Groups

\begin{tabular}{|c|c|c|c|c|c|c|}
\hline \multirow{2}{*}{$\begin{array}{l}\text { Variables } \\
\text { Frequency }\end{array}$} & \multicolumn{3}{|c|}{ Day 1 - Day 7 (Initial Recovery) } & \multicolumn{3}{|c|}{ Day 7 - Day 21 (Subsequent Recovery) } \\
\hline & Control & Smoke exposure & Pvalue & Control & Smoke exposure & Pvalue \\
\hline 4620 & $-0.38(2.21)$ & $0.60(2.97)$ & 0.603 & $0.00(1.15)$ & $0.30(2.33)$ & 0.822 \\
\hline 5040 & $-0.12(1.03)$ & $-0.33(2.08)$ & 0.866 & $0.00(1.15)$ & $1.17(1.89)$ & 0.354 \\
\hline 5880 & $-0.88(0.75)$ & $-0.75(0.29)$ & 0.766 & $-0.38(2.14)$ & $0.75(1.44)$ & 0.416 \\
\hline 6720 & $0.25(1.50)$ & $1.10(2.20)$ & 0.532 & $0.00(1.82)$ & $-0.10(1.75)$ & 0.936 \\
\hline 7500 & $-0.25(1.85)$ & $1.25(2.06)$ & 0.320 & $-0.50(1.68)$ & $0.38(2.14)$ & 0.544 \\
\hline 8340 & $-0.12(2.29)$ & $1.75(2.06)$ & 0.269 & $-0.50(1.91)$ & $0.25(3.71)$ & 0.732 \\
\hline 9180 & $0.50(1.91)$ & $4.50(1.91)$ & 0.082 & $0.62(2.84)$ & $1.75(2.06)$ & 0.555 \\
\hline 9600 & $-1.00(1.41)$ & $5.12(2.39)$ & 0.031 & $0.50(0.58)$ & $0.62(1.11)$ & 0.894 \\
\hline 9960 & $-1.62(3.57)$ & $4.88(2.10)$ & 0.015 & $0.38(0.75)$ & $1.62(1.25)$ & 0.247 \\
\hline
\end{tabular}

several months (42). Since there are limited animal studies on cigarette smoking, the temporary effects of smoke on hearing and histological/physiological changes are not clear. However, in the present study, this level of subacute smoke exposure for 10 consecutive days resulted in temporary and reversible biological and physiological changes; also, the endogenous defense system of the cochlea was able to recover.

The mentioned findings have been confirmed in a review article on 37 animals. Changes were observed in the glutathione level and oxidative stress markers in the first 6 hours after acute cigarette smoke exposure, while these parameters returned to the normal range within 24 hours, suggesting the protective mechanism of cells against oxidative stress from smoke (2). Additionally, this recovery might be due to the exertion of free radical products after acute smoke exposure, as levels of both free and esterified $\mathrm{F}_{2}$-isoprostanes (as lipid peroxidation products) become significantly lower than the plasma levels, measured during smoking after 2 weeks of abstinence (43).

In the current research, the histological effects on the cochlea were not investigated, while in another study, nicotine injection for 1 month in guinea pigs resulted in the damage of stereocilia, including disorganization, bent and limp (or complete loss), and expansion of the surrounding supporting cells (44). Evidence suggests that buckling of pillar bodies temporarily uncouples the OHC stereocilia from the tectorial membrane; also, hair cell stimulation is attenuated by this uncoupling (45). Therefore, the degenerated number of hair cells may be larger when more TTSs are sustained by the cochlea. Irreversible hearing loss is expected if animals are exposed to cigarette smoking with higher concentrations of TSP and CO.

Since workers are exposed to cigarette smoke and dif- ferent ototoxic agents at workplace for a long time, it is necessary to investigate the chronic or subchronic effects of smoke on permanent hearing damage through designing more in vivo studies. This study could not investigate hearing changes at frequencies higher than $10,000 \mathrm{~Hz}$ due to instrumental limitations. As more hearing attenuation was detected at higher frequencies after 1 day of exposure, use of instruments with a greater broad frequency range is recommended to obtain more accurate results about the effects of cigarette smoke on hearing loss.

\section{Acknowledgments}

This study was supported by Tarbiat Modares University, Tehran, Iran (2015 - 2016). The authors would like to thank Mostafa Hoseinzade, Mohammad Hasan Rezaei, and Mehdi Sadeghi, who helped design and construct the smoking machine.

\section{References}

1. Johnson AC, Morata TC. Occupational exposure to chemicals and hearing impairment. Gothenburg, Sweden: University of Gothenburg \& authors; 2010.

2. van der Vaart H, Postma DS, Timens W, ten Hacken NH. Acute effects of cigarette smoke on inflammation and oxidative stress: a review. Thorax. 2004;59(8):713-21. doi: 10.1136/thx.2003.012468. [PubMed: 15282395].

3. Ferrite S, Santana V. Joint effects of smoking, noise exposure and age on hearing loss. Occup Med (Lond). 2005;55(1):48-53. doi: 10.1093/occmed/kqio02. [PubMed: 15699090].

4. Barone JA, Peters JM, Garabrant DH, Bernstein L, Krebsbach R. Smoking as a risk factor in noise-induced hearing loss. $J$ Occup Med 1987;29(9):741-5. [PubMed: 3681506].

5. Fabry DA, Davila EP, Arheart KL, Serdar B, Dietz NA, Bandiera FC, et al. Secondhand smoke exposure and the risk of hearing loss. Tob Control. 2011;20(1):82-5. doi: 10.1136/tc.2010.035832. [PubMed: 21081307]. 
6. Jacobsen LK, Slotkin TA, Mencl WE, Frost SJ, Pugh KR. Genderspecific effects of prenatal and adolescent exposure to tobacco smoke on auditory and visual attention. Neuropsychopharmacology. 2007;32(12):2453-64. doi: 10.1038/sj.npp.1301398. [PubMed: 17375135].

7. Mizoue T, Miyamoto T, Shimizu T. Combined effect of smoking and occupational exposure to noise on hearing loss in steel factory workers. Occup Environ Med. 2003;60(1):56-9. doi: 10.1136/oem.60.1.56. [PubMed: 12499458].

8. Rogha M, Hashemi M, Askari N, Abtahi SH, Sepehrnejad M, Nilforoush MH. Cigarette smoking effect on human cochlea responses. Adv Biomed Res. 2015;4:148. doi: 10.4103/2277-9175.161575. [PubMed: 26380233].

9. Virokannas H, Anttonen $\mathrm{H}$. Dose-response relationship between smoking and impairment of hearing acuity in workers exposed to noise. Scand Audiol. 1995;24(4):211-6. doi: 10.3109/01050399509047538. [PubMed: 8750748].

10. Cruickshanks KJ, Klein R, Klein BE, Wiley TL, Nondahl DM, Tweed TS. Cigarette smoking and hearing loss: the epidemiology of hearing loss study. JAMA. 1998;279(21):1715-9. doi: 10.1001/jama.279.21.1715. [PubMed: 9624024].

11. Nakanishi N, Okamoto M, Nakamura K, Suzuki K, Tatara K. Cigarette smoking and risk for hearing impairment: a longitudinal study in Japanese male office workers. JOccup Environ Med. 2000;42(11):1045-9. doi: 10.1097/00043764-200011000-00001. [PubMed: 11094781].

12. Paschoal CP, Azevedo MF. Cigarette smoking as a risk factor for auditory problems. Braz J Otorhinolaryngol. 2009;75(6):893-902. doi: 10.1016/S1808-8694(15)30556-5. [PubMed: 20209294].

13. Siegelaub AB, Friedman GD, Adour K, Seltzer CC. Hearing loss in adults: relation to age, sex, exposure to loud noise, and cigarette smoking. Arch Environ Health. 1974;29(2):107-9. doi: 10.1080/00039896.1974.10666542. [PubMed: 4835178].

14. Starck J, Toppila E, Pyykko I. Smoking as a risk factor in sensory neural hearing loss among workers exposed to occupational noise. Acta Otolaryngol. 1999;119(3):302-5. doi: 10.1080/00016489950181288. [PubMed: 10380732].

15. Mom T, Bonfils P, Gilain L, Avan P. Vulnerability of the gerbil cochlea to sound exposure during reversible ischemia. Hear Res. 1999;136(12):65-74. doi: 10.1016/S0378-5955(99)00109-4. [PubMed:10511625]

16. Fechter LD, Chen GD, Rao D, Larabee J. Predicting exposure conditions that facilitate the potentiation of noise-induced hearing loss by carbon monoxide. Toxicol Sci. 2000;58(2):315-23. doi 10.1093/toxsci/58.2.315. [PubMed: 11099644].

17. Johnson AC, Juntunen L, Nylen P, Borg E, Hoglund G. Effect of interaction between noise and toluene on auditory function in the rat. Acta Otolaryngol. 1988;105(1-2):56-63. doi: 10.3109/00016488809119446. [PubMed: 3341162]

18. Khavanin A, Mortazavi SB, Mirzaei R, Imani H, Kazemnejad A, Akbari $M$. The comparison of effects of toluene, especially noise and toluene along with noise per Auditory Brain Stem response on rabbit [In Persian]. Tabib-E-Shargh. 2007;9(3):171-80.

19. Lataye R, Campo P. Combined effects of a simultaneous exposure to noise and toluene on hearing function. Neurotoxicol Teratol. 1997;19(5):373-82. doi: 10.1016/s0892-0362(97)00049-4. [PubMed 9380004].

20. Lataye R, Campo P, Loquet G. Combined effects of noise and styrene exposure on hearing function in the rat. Hear Res. 2000;139(1-2):8696. doi: 10.1016/S0378-5955(99)00174-4. [PubMed:10601715].

21. Liu S, Zhang K, Wu S, Ji X, Li N, Liu R, et al. Lead-induced hearing loss in rats and the protective effect of copper. Biol Trace Elem Res. 2011;144(1 3):1112-9. doi: 10.1007/s12011-011-9142-6. [PubMed: 21750944].

22. Motalebi Kashani M, Khavanin A, Alameh A, Mirzaei R, Akbari M. Effect of simultaneous noise and carbon monoxide exposure on rabbits' auditory brain stem response [In Persian]. Feyz. 2010;13(4):261-70.

23. Rao DB, Fechter LD. Increased noise severity limits potentiation of noise induced hearing loss by carbon monoxide. Hear Res. 2000;150(1-2):206-14. doi: 10.1016/S0378-5955(00)00202-1. [PubMed
11077204].

24. Young JS, Upchurch MB, Kaufman MJ, Fechter LD. Carbon monoxide exposure potentiates high-frequency auditory threshold shifts induced by noise. Hear Res. 1987;26(1):37-43. doi: 10.1016/03785955(87)90034-7. [PubMed: 3558142].

25. Jardim JR, Bizeto L, Fleig Mayer A, Camelier A, Rosa FW, Oliveira D, et al. [An inhalation chamber model for controlled studies of tobacco smoke toxicity in rodents]. Arch Bronconeumol. 2010;46(9):455-8. doi: 10.1016/j.arbres.2010.05.012. [PubMed: 20624668].

26. Prusaczyk WK, Fischer GJ. A small-animal inhalation chamber for short-to-intermediate term exposure. Behav Res Methods Instrum. 1983;15(3):369-73. doi: 10.3758/bf03203661.

27. Laskin S, Drew RT. An inexpensive portable inhalation chamber. Am Ind Hyg Assoc J. 1970;31(5):645-6. doi: 10.1080/0002889708506307. [PubMed: 5275099].

28. O'Shaughnessy PT, Achutan C, O'Neill ME, Thorne PS. A small whole-body exposure chamber for laboratory use. Inhal Toxicol. 2003;15(3):251-63. doi: 10.1080/08958370304504. [PubMed: 12579456].

29. Shraideh ZA, Awaida W, Najjar H. A modified smoking machine for monitoring the effect of tobacco smoke on albino rats. Jordan J Biol Sci. 2011;4(2):109-12.

30. Wong BA. Inhalation exposure systems: design, methods and operation. Toxicol Pathol. 2007;35(1):3-14. doi: 10.1080/01926230601060017. [PubMed: 17325967].

31. Guerin MR. The FTC cigarette test method for determining tar, nicotine, and carbon monoxide yields of U.S. cigarettes. 7 ed. US: Department of health and human services; 1996.

32. Hatzopoulos S, Petruccelli J, Laurell G, Finesso M, Martini A. Evaluation of anesthesia effects in a rat animal model using otoacoustic emission protocols. Hear Res. 2002;170(1-2):12-21. doi: 10.1016/S03785955(02)00448-3. [PubMed: 12208537].

33. Negley C, Katbamna B, Crumpton T, Lawson GD. Effects of cigarette smoking on distortion product otoacoustic emissions. J Am Acad Audiol. 2007;18(8):665-74. doi:10.3766/jaaa.18.8.4. [PubMed: 18326153].

34. Mehrparvar AH, Davari MH, Mollasadeghi A, Vahidi MR, Mostaghaci M, Bahaloo M, et al. Hearing Loss due to Carbon Monoxide Poisoning. Case Rep Otolaryngol. 2013;2013:940187. doi: 10.1155/2013/940187. [PubMed: 23762709].

35. Dengerink HA, Lindgren FL, Axelsson A. The interaction of smoking and noise on temporary threshold shifts. Acta Otolaryngol. 1992;112(6):932-8. doi: 10.3109/00016489209137493. [PubMed: 1481663].

36. Howard G, Wagenknecht LE, Burke GL, Diez-Roux A, Evans GW, McGovern $\mathrm{P}$, et al. Cigarette smoking and progression of atherosclerosis: The Atherosclerosis Risk in Communities (ARIC) Study. JAMA. 1998;279(2):119-24. doi:10.1001/jama.279.2.119. [PubMed: 9440661].

37. Lacerda A, Leroux T, Morata T. [Ototoxic effects of carbon monoxide exposure: a review]. Pro Fono. 2005;17(3):403-12. doi: 10.1590/S010456872005000300014. [PubMed:16389797].

38. Dugan LL, Choi DW. Basic Neurochemistry: Molecular, Cellular and Medical Aspects. 6 ed. Washington: University: Department of Neurology; 1999.

39. Vannucci SJ, Hagberg H. Hypoxia-ischemia in the immature brain. J Exp Biol. 2004;207(Pt 18):3149-54. doi: 10.1242/jeb.01064. [PubMed: 15299036].

40. Wild DC, Brewster MJ, Banerjee AR. Noise-induced hearing loss is exacerbated by long-term smoking. Clin Otolaryngol. 2005;30(6):517-20. doi: 10.1111/j.1749-4486.2005.01105.x. [PubMed:16402976].

41. Ahn JH, Joo HS, Suh JK, Kim H, So HS, Chung JW. Effects of cigarette smoking on hearing recovery from noise-induced temporary hearing threshold shifts in mice. Otol Neurotol. 2011;32(6):926-32. doi: 10.1097/MAO.0b013e318225575a. [PubMed: 21725268].

42. Aftab A, Quraishi S. Etiological causes of reversible sensorineural hearing loss. Internet J Otorhinolaryngology. 2006;4(2).

43. Morrow JD, Frei B, Longmire AW, Gaziano JM, Lynch SM, Shyr Y, 
et al. Increase in circulating products of lipid peroxidation (F2isoprostanes) in smokers. Smoking as a cause of oxidative damage. $N$ Engl J Med. 1995;332(18):1198-203. doi: 10.1056/NEJM199505043321804. [PubMed: 7700313].

44. Abdel-Hafez AM, Elgayar SA, Husain OA, Thabet HS. Effect of nicotine on the structure of cochlea of guinea pigs. Anat Cell Biol.
2014;47(3):162-70. doi: 10.5115/acb.2014.47.3.162. [PubMed: 25276475]. 45. Nordmann AS, Bohne BA, Harding GW. Histopathological differences between temporary and permanent threshold shift. Hear Res 2000;139(1-2):13-30. doi: 10.1016/S0378-5955(99)00163-X. [PubMed 10601709]. 